\title{
O estudante de medicina e seu percurso acadêmico: uma análise de postagens sobre sofrimentos
}

\author{
The medical student and his academic career: an analysis of postings \\ of suffering
}

Andréia Ferreira dos Santos ${ }^{\mathbf{1}}$, Lana Veras ${ }^{\mathbf{1}}$

DOI: $10.1590 / 0103-1104202113012$

RESUMO Em uma contemporaneidade que valoriza a felicidade performática e medicaliza a vida, a formação médica é disparadora de questões diversas. A vivência acadêmica, que já anuncia o futuro cotidiano profissional, é perpassada por exigências e comportamentos adoecedores, os quais comprometem a saúde dos estudantes como um todo. Nesse sentido, buscou-se, por meio da análise de postagens públicas na rede social Instagram, de outubro de 2018 a abril de 2019, compreender as manifestações de sofrimento desses indivíduos a partir do que decidem expor à comunidade. Os resultados sinalizam para a naturalização da perda de qualidade de vida, a propagação de um discurso meritocrático de superação das adversidades, bem como o uso das redes sociais como estratégia de enfrentamento e pertença. Reforçam, além disso, a necessidade de se dar continuidade à investigação desses discursos, visto que anunciam um cenário que exige atenção.

PALAVRAS-CHAVE Educação médica. Redes sociais. Saúde mental.

\begin{abstract}
In a contemporary age that values performative happiness and medicalizes life, medical training is a trigger for different issues. The academic experience, which already announces the daily professional future, is permeated by demands and sickening behaviors, which compromise the health of the students as a whole. In this sense, through the analysis of public posts in the Instagram social network, from October 2018 to April 2019, it was sought to understand the manifestations of suffering of these individuals from what they decide to expose to the community. The results signal the naturalization of the loss of quality of life, the propagation of a meritocratic discourse of overcoming adversity, as well as the use of social networks as a strategy of confrontation and belonging. They also reinforce the need to continue investigating these discourses, since they announce a scenario that requires attention.
\end{abstract}

KEYWORDS Education, medical. Social networking. Mental health.

1 Universidade Federal do Delta do Parnaíba (UFDPar) - Piauí (PI), Brasil. 


\section{Introdução}

"Permita-se adoecer!"”: o conselho de uma estudante de medicina, dado em uma postagem pública na rede social Instagram, é disparador de questões relacionadas à vivência acadêmica nos cursos médicos. Em seu desabafo, ela fala sobre a indisponibilidade de tempo, a falta de sono, a mudança na imunidade, os sentimentos de insegurança e de como tudo isso afeta a saúde do universitário. O texto torna evidente não apenas o processo de adoecimento advindo de uma carga horária exaustiva, a cobrança por desempenho e os desafios emocionais, mas, também, a sua naturalização como parte do percurso formativo.

A formação médica esperada na contemporaneidade baseia-se em uma educação conduzida por autonomia, autoconstrução do conhecimento e responsabilidade social. O graduando deve ser comprometido, trocar saberes, fazer reflexões críticas sobre a situação de saúde e propor soluções ${ }^{2}$. Essas diretrizes muito colaboram para a transformação de uma medicina que há pouco mostrava-se dissociada do cuidado em saúde que considera as demandas sociais e o indivíduo em sua totalidade. A fim de tornar isso possível, as metodologias ativas, que apostam no protagonismo do estudante no processo ensino-aprendizagem por meio de atividades educativas dinâmicas e contato prévio com práticas do futuro exercício profissional, têm sido incorporadas às propostas curriculares.

Percebe-se, entretanto, uma escassez de espaços de discussão e orientação quanto às necessidades físicas e psicológicas desses universitários, as quais são demandas muito pertinentes à atenção das universidades. Vries-Erich, Dorman, Boerboom, Jaarsma e Helmich ${ }^{3}$ apontam um empenho da graduação médica em incentivar os alunos a se identificarem com um discurso de competências que os tornaria 'bons médicos', criando um campo em que expressar e compartilhar certas experiências afetivas mostra-se inadequado. Assim, eles passam a performar de acordo com as expectativas correspondentes a essa identidade, negociando com eles mesmos as atitudes e os sentimentos que podem - e devem - demonstrar.

Nesse sentido, pode-se pensar, para além dos corpos adoecidos, nas porções de sofrimento diário que precisam ser engavetadas pelos graduandos nesse contexto típico de negociação dos próprios limites, para que não fiquem às margens de aprovação, o que implica alto custo para a sua saúde mental.

É preciso refletir, também, sobre a relação entre esse cenário de exigências pelo ideal e o 'estar no mundo' contemporâneo. Audino, Pacheco-Ferreira e Herzo 4 resgatam o percurso da tolerância social com os sentimentos de tristeza: se a melancolia já foi associada a estados profundos da alma e à genialidade, hoje ganha status de "insuficiência e miséria afetiva"4(54). O sofrer perde espaço em tempos que associam, sinalizam as autoras, estados subjetivos genuínos a classificações patológicas passíveis, inclusive, de medicalização.

Certamente, é possível associar essa intolerância com a máxima atual de busca de prazeres instantâneos e estados de bem-estar em uma lógica de felicidade imperativa - o 'ser feliz' cresce como fio condutor necessário de vida à medida que declina a relevância das vivências de dor. O cotidiano, servido de um cardápio farto de situações que trazem medo, insegurança, raiva e tristeza, torna-se palco de incessantes tentativas não só de combater todos eles, mas, também, de potencializá-los.

Se os estados de plenitude e bem-estar que, supostamente, podem ser comprados, ranqueados e quimicamente conquistados ganham tom de dever, podem-se imaginar os conflitos suscitados no estudante de medicina. Inseridos na conjuntura de excesso de demandas curriculares, pouco espaço para o cuidado da própria saúde, contato com temas como o enfrentamento da morte e com o sofrimento do outro, precisam performar como potenciais 'bons médicos' e como indivíduos que conseguem ser motivados e felizes, apesar de tudo. Mia Couto ${ }^{5}$ associa felicidade com 
a possibilidade de "visitarmos e sermos visitados por outras sensibilidades"5(54). Indo ao encontro do que diz o poeta moçambicano, pode-se refletir: se é a omissão dos afetos e sensibilidades que sustenta a adequação desses sujeitos ao 'caminho certo' no curso, estariam eles realmente felizes?

\section{Contemporaneidade: felicidade, consumo e desempenho}

Em tempos de uma busca inesgotável de felicidade, Solnit ${ }^{6}$ apresenta que a pergunta "Você é feliz?"6(16) surge com uma naturalidade reflexa e com a pressuposição de que, como se munidos de uma receita, soubéssemos 'como deve ser uma vida feliz'. A autora discorre sobre a atitude contemporânea de tentar seguir um roteiro padrão a fim de alcançar o bem-estar e a autorrealização, realidade que dialoga com o que Veras ${ }^{7}$ coloca como “check-list da felicidade"7(122), uma série de pré-requisitos - relacionados a saúde, corpo, relações, formação e trabalho - que, aparentemente, asseguram um estado de satisfação.

Segundo Mansano e Lima ${ }^{8}$, esse estado figura como um desejo social compartilhado no contexto de um projeto contemporâneo em que o 'ser feliz' é compulsório?. Sendo assim, tende-se a desconsiderar as múltiplas possibilidades de experimentar emoções outras, como a dor e a frustração, como parte da vivência cotidiana. Se o viver é indissociável dos sentimentos corriqueiros distantes da felicidade idealizada, apontam os autores, esta é inalcançável como condição permanente.

A efemeridade dessa desejada sensação de plenitude alia-se à lógica capitalista de consumo, que se veste de solução para a satisfação incessante de desejos individuais, à disposição de todos, a fim de legitimar o modo de vida contemporâneo ${ }^{10}$. De acordo com os autores, valores são materializados em produtos e caracterizam a "felicidade mensurável"10(223). Solnit"11 utiliza o conceito de 'tirania do quantificável', de Chip Ward, que se relaciona com o consumo e/da felicidade, quando supõe a precedência do que pode ser medido sobre o que não é - se não é mensurável, não é útil.

Sob essa lógica de medida, alinhada com o imperativo atual de autonomia e gestão de si12, vive uma sociedade que tanto constrói quanto se submete a moldes performativos. A quantificação do bem-estar é acompanhada da sensação de insuficiência constante e da competição: é preciso ser mais e melhor ${ }^{\mathbf{7}}$. Ferraz ${ }^{\mathbf{1 3}}$ contribui quando destaca um funcionamento avaliativo sobre os indivíduos na contemporaneidade, o que gera atitudes performáticas de prestação de contas de desempenhos. A maximização destes, segundo a filósofa, é buscada em um contexto no qual "produzem-se interminavelmente graus diferenciados e certamente mais sutis de reprovação ou exclusão"13(36), os quais alimentam um sistema social insaciável de exigências.

\section{Medicalização do viver}

O indivíduo como condutor do próprio percurso para o sucesso pessoal: para ele, mostra Perrusi14, "seu destino é sua responsabilidade e seu desempenho, construção solitária"14(148). Em contrapartida à exaltação do bem-estar contemporâneo, o sofrimento figura como inadaptação e precisa ser eliminado. Certas emoções cotidianas - angústia, ansiedade, insegurança - passam a ganhar adjetivos como inaceitáveis ou intoleráveis em um momento de empenho normativo que tenta assegurar que o olhar para o mundo seja convencional: há de ser/estar feliz. Os que não se sentem sempre capazes de corresponder apenas às 'boas' emoções experimentam sensações de confusão e desajuste ${ }^{15}$.

Nesse contexto de supressão das dores do eu, ganha destaque a banalização do sofrimento psíquico, na medida em que, equiparado com a dor física, torna-se passível de medicalização. Em tempos de urgência para eliminar os sentimentos que sinalizam para o fracasso do mal-estar, o uso de medicamentos mostra-se como saída imediata e legitimada 
pela descaracterização do processo de sofrer: 0 indivíduo é visto como "corpo-máquina"14(154) que performa funções a partir da autonomia ${ }^{14}$. No cenário de exaltação ao desempenho, as tecnologias médicas são buscadas não apenas para curar ou aliviar, mas, também, para otimizar e aperfeiçoar o sujeito ${ }^{16}$.

Bezerra Jr. ${ }^{12}$ observa que há, atualmente, um aumento da aceitação da sociedade quanto a essa medicalização de vivências subjetivas, o que ocorre junto à redução da tolerância com as diferenças ${ }^{7}$. O autor relaciona esse processo com a fronteira cada vez mais tênue entre o que é sentido e a possibilidade de que se torne um diagnóstico, intimamente ligado a uma certa tendência de patologização das experiências nítida nos manuais da psiquiatria. Nesse sentido, recorre-se às contribuições de Canguilhem ${ }^{\mathbf{1 7}}$ quanto à limitação dos conceitos de 'normal' e 'patológico', que não abrangem, em si, os diversos contextos e possibilidades possíveis aos sujeitos.

Patologizar a tristeza, em meio ao panorama de medicalização, gera riscos tanto no que diz respeito à expressão das subjetividades dos indivíduos quanto pela utilização irrestrita de fármacos como intervenção no corpo ${ }^{18}$. Além disso, reforça um 'horizonte normativo' de valores que, em consonância com a lógica do consumo, contempla a promessa impossível de 'felicidade química', vislumbrada como via de acesso às expectativas sociais. Quando estas referem-se a uma postura performática de desempenho individual, avalia Perrusi ${ }^{14}$, permitem que "se existe a dor entre a heteronomia e a autonomia, deixem passar o psicotrópico, pois é a solução"14(154).

Assim, a tentativa incessante de medicalizar a vida mostra-se, segundo Christofari, Freitas e Baptista19, como "um rastro de pólvora que se infiltra e se expande rapidamente de forma quase incontrolável em todas as esferas da vida humana"19(1086), atingindo, inclusive, as maneiras de ser e de aprender em uma contemporaneidade em que a medicina produz discursos que são internalizados.

\section{O trajeto formativo e o 'ser médico'}

A educação médica tem passado por transformações. Busca-se, em contraponto a um modelo convencional com componentes curriculares engessados e distantes das práticas, um percurso que aponta para uma formação generalista e sensível às questões sociais. Para atender a essa realidade, mudanças relativas ao processo de ensino-aprendizagem têm colocado o estudante de medicina como autor do seu próprio aprendizado, autônomo e participativo, em um sistema que não mais obedece à lógica de instrução vertical da docência ${ }^{20}$.

Demandas do campo da saúde e dos acadêmicos, de acordo com os autores, instigam a necessidade de tais mudanças, as quais visam a garantir os anseios por futuros profissionais qualificados. A aposta parece ser na utilização de metodologias ativas, que descontroem essa ideia de domínio do conhecimento pelo docente - que passa a figurar como facilitador - e tornam o aluno responsável pelas próprias buscas, formulações e conclusões relacionadas aos conteúdos.

Com relação a esses anseios, fala-se em um 'tipo ideal' de perfil almejado para os estudantes de cursos médicos, futuros profissionais da saúde, que envolve competência, proatividade, humanidade, responsabilidade, consciência, solidariedade, engajamento e participação. Na sua trajetória formativa, esses indivíduos, como já discutido, são colocados como responsáveis pela autoconstrução e pelas transformações rumo ao alcance dessa série de valores ${ }^{21}$. Mais que conhecimentos técnicos, esperam-se deles competências transversais que despertem a criticidade, possibilitadas pelo que Ferreira ${ }^{22}$ engloba como "humanidades médicas"22(291).

Nesse contexto de transformações ainda em curso e tantas exigências, Almeida ${ }^{23}$ pontua que os graduandos se sentem pressionados por uma sensação de dever e de saber absoluto, premissas do 'ser médico' que atropelam o 'ser eu'. O estudante, durante a formação, passa a se identificar com o 'ser médico' à 
custa da negação das suas subjetividades, o que influencia sua relação com o sofrimento do eu e do outro. A médica sinaliza como plano de fundo dessa realidade a desumanização e a construção de um discurso da medicina que exige e fundamenta relações de poder: estas, segundo ela, iniciadas nos próprios ritos institucionais, como os trotes, anunciam e legitimam a severidade das experiências pelas quais vão passar esses indivíduos.

Esse cenário torna-se potencialmente adoecedor, ao passo que desafia os estudantes a superarem os próprios limites a fim de corresponderem às tantas expectativas do tipo ideal. Em meio a angústias diversas, acabam lançando mão de mecanismos de defesa, "isolando-se em uma crença onipotente"23(748), que faz parte do discurso médico, e negando suas características e necessidades humanas básicas. Destaca-se, nesse sentido, o que Andrade et al. ${ }^{24}$ enunciam quanto à sistemática preocupação dos cursos médicos com o aprimoramento do ensino, mas não com a saúde mental dos sujeitos enquanto educandos.

\section{Há espaço para o sofrimento na educação médica?}

As dificuldades acadêmicas do estudante de medicina, quando investigadas, parecem sobressair no universo de experiências ao longo do curso. Tanaka, Furlan, Branco e Valerio 25 observam que fatores como a carga horária excessiva, a desorganização pessoal, a precária assistência da faculdade, o novo ritmo de vida e a distância da família são os mais relatados quanto à caraterização da vivência acadêmica. Somam-se a elas, de acordo com Andrade et al. ${ }^{24}$, privação de lazer, medo de não ser um bom médico, problemas nas relações interpessoais, insatisfação com o comportamento sexual e até mesmo vontade de desistir do curso.

Essa conjuntura, segundo estes, relaciona-se com o ambiente competitivo do curso, a exigência de excelência, o contato com a morte e com o enfrentamento de sofrimentos. Vicensi ${ }^{26}$ aponta para uma formação médica deficiente, na qual não há preparo quanto aos sentimentos e emoções que surgem na preparação acadêmica e na atuação profissional do médico. A autora discorre, também, sobre um distanciamento dos temas de enfrentamento do sofrer em grande parte dos currículos, o que leva ao acúmulo de sentimentos dos estudantes/profissionais na prática cotidiana e à dificuldade de buscarem ajuda.

No contexto desse sofrimento acumulativo e silencioso, mostram-se como escapes mecanismos de defesa e formas de 'atenuar' as dores psíquicas. A utilização de psicotrópicos e do álcool, por exemplo, tem aumentado entre os graduandos de cursos médicos, o que indica a busca de formas outras de enfrentamento que não a procura de ajuda profissional dentro ou fora da universidade ${ }^{24}$.

Em torno do 'passar em medicina', (re) afirmam-se mitos e projeções, pessoais e familiares sobre o significado da capacidade de adentrar esse universo médico de formação e profissão ${ }^{27}$. A idealização de cura como definição de sucesso terapêutico instiga nos estudantes certa onipotência - o herói que combate a morte - e ilusões, visto que entram e entrarão em contato com situações irreversíveis de perdas ${ }^{\mathbf{2 8}}$. Assim, fica evidente a demanda por uma formação sensível à questão humana de assumir fragilidades. Os universitários implicam-se com situações de doença, dor e morte do outro e com as suas vivências próprias, produzindo angústias que precisam ter voz durante a trajetória acadêmica ${ }^{\mathbf{2 6}}$.

Busca-se neste artigo, assim, discutir sobre as experiências subjetivas do estudante relacionadas aos sofrimentos associados à graduação médica. Dialogando com a demanda de pesquisas sobre a propagação e o manejo de discursos sobre sentimentos nos 'artefatos midiáticos', apontada por Freire Filho ${ }^{15}$, bem como sobre as manifestações emotivas nesses ambientes, analisaram-se textos públicos divulgados no Instagram que provocaram as autoras e as permitiram percorrer os caminhos possíveis de compreensão das questões levantadas. 


\section{Material e métodos}

O percurso de desenvolvimento do tema deste estudo foi guiado por uma abordagem qualitativa, a fim de considerar as subjetividades na construção das relações entre o diálogo bibliográfico apresentado e os objetos de investigação. Essa escolha justifica-se pela potencialidade desse tipo de pesquisa em desvelar os sentidos orientadores de ações humanas, bem como em desconstruir a separação rígida entre objetividade e subjetividade, principalmente no contexto da investigação em saúde ${ }^{29}$.

No sentido de compreender fenômenos a partir de informações que ainda não foram analisadas ou sistematizadas, o método escolhido foi a pesquisa documental. Kripka, Scheller e Bonotto ${ }^{30}$ destacam essa ferramenta metodológica como criadora de novas possibilidades e conhecimentos, contribuindo, assim, para a área na qual o objeto de estudo se insere. Isso dialoga com a escolha da pesquisa qualitativa, que, segundo Minayo ${ }^{31}$, contribui para a ciência de forma universal a partir da "compreensão de processos semelhantes que ocorrem com os seres humanos frente aos mesmos desafios"31(16).

Nessa perspectiva, optou-se pela seleção de material das mídias digitais, partindo da relevância do seu papel na comunicação e interatividade contemporâneas. Freitas ${ }^{32}$ relaciona a utilização dos ambientes digitais para a construção de perfis de indivíduos que elaboram e (re)afirmam, constantemente, a representação de si: gerenciam impressões e tornam-se imagem espelhada do conteúdo que publicam. Assim, esses espaços mostram-se como territórios para potencial compreensão do objetivo desta pesquisa.

Os documentos inclusos na busca foram postagens no modo público da rede social on-line Instagram que anunciassem a temática de vivência do sofrer do estudante de medicina, bem como os comentários resultantes delas. Optou-se por um procedimento de busca através de páginas de hashtags, caracterizadas graficamente como \#, que "mostram todas as publicações públicas que foram compartilhadas com aquela hashtag"33. A fim de tornar a busca específica para o conteúdo desejado, as escolhidas foram \#medicina, \#estudantedemedicina, \#foconojaleco, \#medporamor, \#medicinadepressao e \#meddadepre.

Foram selecionados materiais coletados no período entre os meses de outubro de 2018 e abril de 2019, o que se justifica pela produção constante de conteúdo nessas redes de fluxo imediato de informações. A pesquisa cursa em acordo com a Resolução $n^{\circ}$ 510/2016 do Conselho Nacional de Saúde, visto que dispõe de informações de acesso público e sem identificação, dispensando a necessidade de submissão ao Comitê de Ética em Pesquisa.

A análise documental das postagens contribuiu para a compreensão, em certa medida, do sofrimento do acadêmico do curso de medicina enquanto compartilhado. Os conteúdos apontam para a existência de um espaço em que há desejo pela expressão das dores do eu relativas ao trajeto formativo, as quais existem em um contexto de intensa exigência por bons desempenhos em diversos aspectos. Buscou-se, desse modo, relacionar as ideias apresentadas com os sentimentos divulgados por esses sujeitos.

\section{Resultados e discussão}

\section{O preço que se paga}

"Antes de ser um bom médico você deve sofrer como um bom estudante"34 é o conteúdo de uma das postagens e muito bem representa a ideia mais propagada por elas, ainda que em diferentes nuances. A frequência de mensagens e de interações com elas, em que observa-se a naturalização do esgotamento físico e mental, despertou atenção para questões como: em que medida o sofrimento dos estudantes de cursos médicos condiz com o esperado nas graduações?

É importante pensar que a lógica de avaliação e exigência de desempenhos, apontada por 
Ferraz $^{\mathbf{1 3}}$, recai sobre os indivíduos em diversos contextos de vida. Espera-se que concessões sejam feitas no sentido de corresponder às expectativas e garantir o que se entende como sucesso, o qual está intimamente ligado à possibilidade de uma vida de consumo. Quando entendidas como resultados de escolhas advindas das responsabilidades necessárias ao viver, elas figuram como essenciais no processo de amadurecimento dos estudantes, visto que a graduação é apenas um desses possíveis contextos.

Nesse sentido, Fiedler ${ }^{35}$ contribui com a constatação de uma diminuição de qualidade de vida do acadêmico de medicina, que perpassa as necessidades físicas (alimentação e sono), relacionais/afetivas, de poder e liberdade, bem como de diversão. Ainda que apareçam como mudanças esperadas devido à adaptação a uma nova vivência, parecem haver determinadas especificidades relativas ao ingresso nos cursos médicos. Considerando que o 'sacrifício' inicia-se desde as tensões pré-vestibulares - associadas a um imaginário social que eleva o status do curso -, a experiência é atravessada por excessivas cobranças, pressões e competitividades ${ }^{35}$ que fragilizam a autoestima e comprometem as estratégias de enfrentamento desses sujeitos.

As postagens analisadas nesta pesquisa corroboram essa colocação quando nelas aparecem, repetidas vezes, conteúdos verbais e não verbais sobre a privação de sono, a alimentação inadequada e uma progressiva perda de integridade física e mental ao longo da formação. Isso é representado, entre outras formas, em tons de humor e com figuras conhecidas/pessoas públicas, pelo envelhecimento explícito em vários 'antes e depois' do ingresso no curso. $\mathrm{O}$ aparecimento frequente dessas mesmas mensagens e a quantidade de interações (curtidas e comentários) refletem a construção da ideia de uma trajetória penosa como lugar-comum no percurso médico, (re)afirmada em um espaço social on-line no qual o estudante se reconhece e se permite comunicar dores - dores estas compartilhadas como necessárias, e, em sua maioria, pela via do humor.
Almeida ${ }^{23}$ fala de um lugar de conflito em que vive esse graduando: coexistem o vislumbrar de uma instância de poder e o sentimento de insuficiência na busca por ela. A autora relaciona essa realidade com a imposição violenta de uma identidade que homogeneíza comportamentos e viola subjetividades. Nessa perspectiva, percebe-se que as dores compartilhadas, já citadas, partem de como o estudante se produz para compor esse todo e encontrar um local de pertencimento, ainda que nele não caibam as suas singularidades. "Não faça medicina se não quer passar noites estudando"36 - eles dizem, curtem e comentam, reproduzindo o caminho que possivelmente os levará à paisagem desejada, ainda que confessem que "todo dia o seu emocional se deteriora um pouco"37.

Além disso, é preciso pensar que a vivência da formação médica implica um contato, bem como uma 'preparação' para lidar com as perdas. Vicensi ${ }^{26}$ pontua o desafio contemporâneo das ciências da saúde em ocuparem-se dos temas da morte e do morrer, os quais ainda remetem a fracassos profissionais - possível desdobramento da ideia do médico herói, percebida e reafirmada na seguinte publicação: "Medicina é uma das poucas profissões em que se pode 'sujar as mãos de sangue' e 'salvar vidas' ao mesmo tempo"38.

Nessa perspectiva, é possível presumir que essa ideia gere ansiedades nesse acadêmico, que experencia a proximidade - presente e futura - com o sofrimento do outro e também com o seu, decorrente desse contato e de questões outras. Se recaem tantas expectativas e anseios sobre os cursos médicos e o reconhecimento que eles trazem, vê-se que o caminho estimulado e aplaudido é o de afrouxar os cuidados com as dores do eu, naturalizá-las a qualquer custo, traço que aparece particular e exaustivamente nos discursos dos estudantes de medicina nessas publicações.

Uma delas diz que, "quando você passa da metade do curso, o cansaço já se torna crônico"39; outra os coloca situados em duas práticas: "Mandar o paciente comer bem, fazer 
atividade física e dormir $8 \mathrm{~h}$ por noite" versus "Comer Salgado de almoço na faculdade, ser sedentário, dormir $4 \mathrm{~h}$ por noite" ${ }^{\mathbf{4 0}}$. Tanto elas quanto os comentários que seguiram essa publicação, “tá mais para: ‘quem não'???!!!”, ou “faça o que eu digo não faça o que eu faço KKKK", para além de irem de encontro com as reflexões propostas, transformam a proposta de categoria em pergunta: qual é o preço que se paga?

\section{O discurso da superação}

Conforme apareceram as declarações de naturalização do sofrimento, surgiram também as que propõem a superação dessa vivência de percalços a fim de alcançar o tão estimado sonho: "Não tem plano B: eu serei médico(a)"41. Ainda que esse desejo faça parte da ideia contemporânea, sob a lógica capitalista, de uma vida que se considera bem-sucedida, e que o apoio compartilhado possa funcionar como forma de enfrentamento das dores, é preciso questionar: como se constrói esse sonho?

O sucesso profissional é um dos aspectos contemplados pela máxima atual de felicidade imperativa. O 'ser feliz' implica sentir-se ou parecer realizado com a profissão, a qual deve proporcionar ao indivíduo reconhecimento social e possibilidades de consumo. Nesse sentido, é importante pontuar que o prestígio associado à carreira médica, fundamentado pela posição social, pela valorização financeira e pelos diversos privilégios, impulsiona a construção - muitas vezes, externa - do sonho pela medicina, aliado ou não a inclinações pessoais e aptidões. Surge, então, uma necessária problematização dos discursos que despontam dessa perspectiva. Exemplifica bem a importância dessa discussão uma mensagem que apareceu duplamente, "o sucesso é a soma de pequenos esforços" ${ }^{\mathbf{4}}$, somada à que dizia ser o impossível "uma questão de opinião"37. Destacam-se aqui duas questões: a redução dos desafios desses estudantes a um mesmo patamar, passível de ser superado, bem como o perigo de uma representação meritocrática. Afinal, as postagens sinalizam que, sejam quais forem os obstáculos - alguns dos quais já mencionados -, deve-se ultrapassá-los com determinação pessoal ou, em síntese, 'fazer por onde'.

Assim, recai sobre os acadêmicos a responsabilização integral pelo seu processo de formação e pelo que surge dele, reforçando a ideia de que a dificuldade de lidar com as exigências e pressões é um fracasso, e não existe espaço para ele. A graduação médica é atravessada, portanto, pela exigência que lhe é peculiar e por uma contemporaneidade que cobra o ideal de um viver individual, feliz, realizado e capaz; este, pela lógica de méritos que reforça os confrontos decorrentes de resultados individuais, torna-se fonte de habituais sofrimentos ${ }^{43}$.

Vê-se, assim, que existem estruturas que são resguardadas quando os sujeitos - nesse caso, estudantes dos cursos médicos - acreditam precisar superar quaisquer impasses, a todo custo, no sentido de garantirem o seu enquadramento na ideia que se tem de vida feliz. Os sofrimentos, sejam de ordem física ou psíquica, ora perdem espaço de existência ora tornam-se apenas 'pedras no caminho' de um projeto de futuro consumista e confortável cujo preço, como vimos, ainda está em aberto.

\section{Anestesias}

\section{Como fazer o próximo bem se nem a gente tá? Muitos fogem da realidade justamente por essa intensificação dos sentimentos. Drogas, amigos, festas, choro, vícios, dormir... cada um encontra uma maneira de descarregar ${ }^{37}$.}

Com essa postagem, apresenta-se uma outra nuance observada ao trafegar pelo Instagram: o investimento desses acadêmicos em escapes que os permitem desafiar os próprios limites, a fim de se adequarem à realidade exigente circundante. Preocupa, entretanto, o fato de que as estratégias praticadas caminham juntamente para o processo de medicalização da vida. Seriam as pílulas a solução? 
Conforme se reforça o imperativo da felicidade no viver contemporâneo, os estados infelizes têm sido cada vez mais negados e insistentemente combatidos. É importante pontuar que, a partir deles, os indivíduos elaboram aprendizados indispensáveis. Segundo Medeiros e Takata ${ }^{44}$, inclusive, eles têm uma dupla função: motivam mudanças e possibilitam o surgimento de estratégias de resistência. O que se vê, entretanto, é o esforço de interdição da tristeza e das infelicidades, facilitada pela disponibilidade tanto de substâncias promissoras para anestesiar os efeitos desses estados quanto de discursos que legitimam esse uso.

"Sem café: ansioso/Com café: ansioso porém focado" 45 . Entre as postagens que sinalizaram essa utilização de substâncias, a maioria estava associada à ingestão excessiva de café. Ainda que a cafeína seja naturalmente usada para 'dar ânimo' ou 'despertar', vê-se nesses discursos uma aceitação incondicional do exagero e que aponta para tentativas incessantes de aliviar os sinais de esgotamento, vistos como obstáculos. Um outro conteúdo visual figurava o café sendo administrado como soro, o que destaca a principal reflexão aqui proposta: em uma lógica que naturaliza excessos, os limites do que pode ser prejudicial à saúde são afrouxados, e, mais uma vez, a qualidade de vida é escanteada.

Nesse sentido, é fundamental, também, situar os cursos médicos como contextos facilitadores desse trânsito de ideias que propõem ultrapassar limites e medicalizar condições sobre as quais a melhor intervenção poderia ser, por exemplo, a adoção de bons hábitos (sono, alimentação e lazer adequados). "Fugir da realidade"37, como colocado pela declaração da estudante, torna-se urgente e desmedido em um cenário de tantos esgotamentos - medos, tristezas, angústias, inseguranças, cansaços, insônias, estresses, tensões, ansiedades, dando espaço para a tal 'felicidade química'.

Nota-se, nessas circunstâncias, o risco tanto de encaixar sujeitos que experimentam situações esperadas na formação e no decorrer da vida em diagnósticos equivocados e consequentes tratamentos medicamentosos (cujo efeito pode ser de longo prazo) quanto de, dada a banalização, oferecer atenção e cuidados insuficientes para os que realmente experenciam quadros patológicos.

Vale aqui citar a conclusão de metanálise feita por Pacheco et al.46, que apontou uma alta prevalência de pesquisas que indicam traços de ansiedade nesses estudantes de cursos médicos brasileiros $(89,6 \%)$, bem como a prevalência agrupada, de 2010 a 2016, dos casos de depressão, ansiedade, outros transtornos mentais comuns e uso abusivo de álcool - de 30,6\% a $32,9 \%$. Dialogam com essa constatação os sucessivos casos de suicídio desses graduandos entre 2018 e 2019.

Vê-se, portanto, uma profunda complexidade na análise das adversidades que surgem na trajetória desses estudantes e dos seus possíveis enfrentamentos diários. Com os artifícios que tentam anestesiar o que pode doer - e o que dói, de fato -, constrói-se a imagem de um 'herói' que, afinal, pode ser quem mais precisa de ajuda: com pílulas ou não.

\section{Publicar, interagir, enfrentar}

"Precisava ler isso hoje (AGORA)" 41; "A cada dia tu me inspira mais e mais a seguir os meus sonhos" $\mathbf{4 2}$. Tais comentários marcam uma potencialidade desse espaço on-line enquanto possibilidade desses estudantes compartilharem emoções e, de alguma forma, encontrarem identificação e pertencimento. Ainda que constitua um veículo dos discursos de naturalização já colocados, pode figurar como um dos únicos ambientes nos quais esses indivíduos se permitem expressar sentimentos relacionados com a vivência do curso.

Enquanto local de reprodução das ideias de 'dores que valem a pena', é interessante resgatar o que Freire Filho ${ }^{15}$ chama de "narrativas sobre emoções" 15 (75), visto que dizem respeito à preservação de uma identidade social - nesse caso, o 'vir a ser' médico. $\mathrm{O}$ autor ressalta: 
Sabedora do que é uma reação emocional conveniente, uma pessoa pode enfatizar em seu relato elementos que configuram sua conduta emotiva como a mais natural e óbvia possível, em determinado contexto ${ }^{15(75)}$.

Para além disso, constitui um espaço de desabafos cuja perspectiva da interação parece favorecer a ideia de diálogo. Assim, em meio às diversas expectativas e às consequentes performances resultantes delas, os estudantes de medicina optam por dividir seus anseios com a sua 'comunidade', ou seja, colegas que estejam passando pelas mesmas experiências'. Nisso, resgata-se que, além de buscar quem compreenda as suas questões, essa escolha parece estar relacionada, também, ao desejo de não decepcionar no que diz respeito à superestimada identificação médica.

Nesse sentido, as postagens e seus desdobramentos - comentários, compartilhamentos, curtidas, hashtags - aparecem como produções de subjetividades associadas a múltiplas questões. Procura-se desabafar, reproduzir, performar, identificar-se, pertencer. Considerando a multifatorialidade do sofrimento psíquico desses acadêmicos e de como ele se manifesta, todas as possíveis formas de expressão devem ser consideradas e valorizadas na medida em que aparecem como tentativas de enfrentamento.

\section{Considerações finais}

O estudo evidenciou, portanto, que a análise da formação médica enquanto atravessamento do estudante pode mover-se por diversas direções, visto que parte do esperado e também de particularidades produzidas pela valorização social dada ao curso. Juntamente com a reformulação das propostas de ensino-aprendizagem, mostra-se fundamental a proposição de um cuidado integral que perpasse aspectos físicos, psicológicos e sociais dos acadêmicos, para além da performance da graduação.

Assim, percebe-se a importância da continuidade das observações, indagações e pesquisas sobre os muitos caminhos possíveis de produção e partilha das afetações desses estudantes, a fim de tecer estratégias de prevenção e intervenção. Ainda que tenham sido encontrados discursos que convergem e representam o grupo, destaca-se que este não é homogêneo e que as disparidades socioeconômicas e identitárias seriam fundamentais para aprofundar a análise.

\section{Colaboradoras}

Santos AF (0000-0002-7908-0060)* e Veras L (0000-0003-1744-652X)* contribuíram igualmente para a elaboração do manuscrito. 


\section{Referências}

1. Dentistamedica (@dentistamedica). "Ficar doente x Faculdade”. Instagram, 3 out 2018. [acesso em 2018 dez 8]. Disponível em: https://www.instagram. com/p/BofIJrClRYo/.

2. Brasil. Ministério de Educação, Conselho Nacional da Educação, Câmara de Educação Superior. Resolução $n^{\circ}$ 3, de 20 de junho de 2014. Institui Diretrizes Curriculares Nacionais do Curso de Graduação em Medicina e dá outras providências. Diário Oficial da União. 20 Jun 2014.

3. Vries-Erich JM, Dornan T, Boerboom TBB, et al. Dealing with emotions: medical undergraduates' preferences in sharing their experiences. Medical Education. 2016; (50):817-828.

4. Audino TF, Pacheco-Ferreira F, Herzo F. O imperativo da felicidade nos dias atuais. Trivium: Est. Interd. 2018; (1):49-59.

5. Couto ME. E se Obama fosse africano? - e outras interinvenções. São Paulo: Companhia das Letras; 2011.

6. Solnit R. A mãe de todas as perguntas: reflexões sobre os novos feminismos. São Paulo: Companhia das Letras; 2017.

7. Veras L. Aqui se jaz, aqui se paga: a mercantilização da morte, do morrer e do luto. Curitiba: Appris; 2015.

8. Mansano SRV, Lima AB. "É melhor viver do que ser feliz”: felicidade, idealização e consumo. REA. 2017 [acesso em 2020 mar 20]; 17(193):78-1. Disponível em: https://periodicos.uem.br/ojs/index.php/EspacoAcademico/article/view/33888.

9. Freire Filho J. Fazendo pessoas felizes: o poder moral dos relatos midiáticos. In: Anais do XIX Encontro da Compós; 2010 jun; Rio de Janeiro. Rio de Janeiro: PUC-Rio, 2010. p. 1-14.

10. Fogaça J, Perez C. Felicidade adjetivada: polifonia conceitual, imperativo social. Intercom - RBCC. 2014; 37(1):217-241.
11. Solnit R. Os homens explicam tudo para mim. São Paulo: Cultrix; 2017.

12. Bezerra JR. A psiquiatria e a gestão tecnológica do bem-estar. In: Freire J, organizador. Ser feliz hoje: reflexões sobre o imperativo da felicidade. Rio de Janeiro: FGV; 2010.

13. Ferraz MCF. Mutações da subjetividade contemporânea: performance e avaliação. Cad. Psicanál. - CPRJ. 2014; 36 (30):31-41.

14. Perrusi A. Sofrimento psíquico, individualismo e uso de psicotrópicos: saúde mental e individualidade contemporânea. Tempo soc. 2015; 27(1):139-159.

15. Freire Filho J. Correntes da felicidade: emoções, gênero e poder. MATRIZes. 2017; 11(1):61-81.

16. Corbanezi E. Transtornos depressivos e capitalismo contemporâneo. Caderno CrH. 2018; 31(83):335-353.

17. Canguilhem G. O normal e o patológico. 7. ed. Rio de Janeiro: Forense Universitária; 2011.

18. Fonte EMM, Santos SA. A regulação biotecnológica do sofrimento e do bem-estar subjetivo: o papel da psicofarmacologia na percepção dos psiquiatras. Est. Sociol. 2015; 2(21):311-343.

19. Christofari AC, Freitas CR, Baptista CR. Medicalização dos Modos de ser e de aprender. Educ. Realid. 2015; 40(4):1079-1102.

20. Machado CDB, Wuo A, Heinzle M. Educação Médica no Brasil: uma análise histórica sobre a formação acadêmica e pedagógica. Rev. Bras. Educ. Médica. 2018; 42(4):66-73.

21. Almeida Filho N, Lopes AA, Santana LAA, et al. Formação Médica na UFSB: II. O Desafio da Profissionalização no Regime de Ciclos. Rev. Bras. Educ. Médica. 2015; 39(1):123-134.

22. Ferreira MA. Educação Médica no Século XXI: o 
desafio da integração da tecnologia e humanidades. Gaz. Médica. 2016; 3(4):156-161.

23. Almeida MT. A ordem médica e a desordem do sujeito na formação profissional médica. Rev. Bioét. (Impri.). 2011; 19(3):741-52.

24. Andrade JBC, Sampaio JJC, Farias LM, et al. Contexto de formação e sofrimento psíquico de estudantes de medicina. Rev. Bras. Educ. Médica. 2014; 38(2):231242.

25. Tanaka MM, Furlan LL, Branco LM, et al. Adaptação de Alunos de Medicina em Anos Iniciais da Formação. Rev. Bras. Educ. Médica. 2016; 40(4):663-668.

26. Vicensi MC. Reflexões sobre a morte e o morrer na UTI: a perspectiva dos profissionais. Rev. bioét. (Impr.). 2016; 24(1):64-72.

27. Feijó DH, Mainardi CR, Valente AL, et al. Dilemas e frustações do estudante de medicina: um estudo transversal. Para Res Med J. 2017; 1(2):1-6.

28. Azevedo NSG, Rocha CF, Carvalho PRA. O enfrentamento da morte e do morrer na formação de acadêmicos de Medicina. Rev. Bras. Educ. Médica. 2011; 35(1):37-43.

29. Taquette SR, Villela WV. Pesquisa qualitativa em medicina. Ciênc. Saúde Colet. 2017; 22(1):4.

30. Kripka RML, Scheller M, Bonotto DL. Pesquisa documental na pesquisa qualitativa: conceitos e caracterização. Rev. Invest. UNAD. 2015; 14(2):55-73.

31. Minayo MCS. Cientificidade, generalização e divulgação dos estudos qualitativos. Ciênc. Saúde Colet. 2017; 22(1):16-17.

32. Freitas KC. O imperativo da \#felicidade na plataforma de rede social Instagram. [dissertação]. Salvador: Universidade Federal da Bahia; 2017.

33. Instagram INC. Central de ajuda: Como faço para ver uma página de hashtag? [acesso em 2019 fev 22].
Disponível em: https://help.instagram.com/458423 657648149 ?helpref=search\&sr=1\&query=hashtag.

34. Medicinaefoda (@medicinaefoda). “Só esperando os humilhados serem exaltados”. Instagram, $16 \mathrm{abr}$ 2019. [acesso em 2019 abr 24]. Disponível em: https:// www.instagram.com/p/BwUiuAUBCYS/.

35. Fiedler PT. Avaliação da qualidade de vida do estudante de medicina e da influência exercida pela formação acadêmica. [tese]. São Paulo: Faculdade de Medicina da Universidade de São Paulo; 2008.

36. Medicinaefoda (@medicinaefoda). “Não faça Medicina”. Instagram, 6 abr 2019. [acesso em 2019 abr 24]. Disponível em: https://www.instagram.com/p/ Bv6hJXnl8HD/.

37. Umdiariodemedicina (@umdiariodemedicina)."Você precisa estar curado para curar os outros”. Instagram, 2 dez 2018. [acesso em 2019 abr 29]. Disponível em: https://www.instagram.com/p/Bq40tVlndyB/.

38. Medicinadescontraida (@medicinadescontraida). "Você pode, você vai conseguir (...)". Instagram, 2 abr 2019. [acesso em 2019 abr 29]. Disponível em: https://www.instagram.com/p/BvwfckDhtg6/.

39. Dentistamedica (@dentistamedica).“Como estudar quando você já está esgotado?”. Instagram, 16 nov 2018. [acesso em 2018 dez 2]. Disponível em: https:// www.instagram.com/p/BqQiWWPhodj/.

40. Sutureskin.com.br (@suturekin.com.br).“Alguém?”. Instagram, 13 mar 2019. [acesso em 2019 mar 20]. Disponível em: https://www.instagram.com/p/Bu8_ ZMUIUYP/.

41. Estetofoco (@estetofoco). “No plan B”. Instagram, 28 dez 2018. [acesso em 2019 abr 29]. Disponível em: https://www.instagram.com/p/Br8XIuJnC2v/.

42. Jupabis (@jupabis). "Passando aqui só pra te lembrar (...)”. Instagram, 26 nov 2018. [acesso em 2019 jan 25]. Disponível em: https://www.instagram.com/p/ BqqOHVoBAns/. 
43. Béhar AH. Meritocracia enquanto ferramenta da ideologia gerencialista na captura da subjetividade e individualização das relações de trabalho: uma reflexão crítica. Rev. Org. Soc. 2019; 26(89):249-268.

44. Medeiros C, Takata R. Do direito à (in)felicidade. ComCiência. 2014; (161):1-3.

45. Meddadepre (@meddadepre)."MeddoCafezao”. Instagram, 6 nov 2018. [acesso 2019 jan 20]. Disponível em: https://www.instagram.com/p/BplweM1BDI8/.
46. Pacheco JP, Giacomin HT, Tam WW, et al. Mental health problems among medical students in Brazil: a systematic review and meta-analysis. Rev. Bras. Psiquiatr. 2017; 39(4):369-378.

Recebido em 11/02/2021

Aprovado em 04/08/2021

Conflito de interesses: inexistente

Suporte financeiro: não houve 